United States Department of Agriculture

Agricultural Research Administration

Bureau of Entomology and Plant Quarantine

\title{
TESTS OF INSECTICIDES FOR CONTROL OF THE PICKLEWORM AND ASSOCIATED INSECTS ON CUCUMBERS AND SQUASH--1948-51
}

\author{
By W. J. Reid, Jr., and F. P. Cuthbert, Jr。 \\ Division of Truck Crop and Garden Insect Investigations 1 /
}

The pickleworm (Diaphania nitidalis (Stoll)) is a serious pest of cucurbit crops in the South Atlantic and Gulf States. It frequently causes considerable damage in adjoining States, and occasionally occurs as far west as Texas, Kansas, Missouri, and Iowa, and as far north as the tier of States extending from Illinois eastward to Connecticut, including New York. Summer squash is its favorite host, but it often severely damages cucumber and muskmelon. Occasionally young tender fruit of winter squash is attacked. The pickleworm is active throughout the winter in the extreme southern part of Florida, where its cultivated or native hosts are available continuously. From this and similar subtropical areas the insect gradually spreads northward each year, and usually appears later in the spring than most insects. Evidently it does not survive the winter as far north as the Carolinas.

The melonworm (Diaphania hyalinata (L.)), a species related to but less destructive and more easily controlled than the pickleworm, has about the same distribution in the United States. In addition, it has been reported from Arizona, New Mexico, and southern California, and adults have been taken in Canada. Apparently it also overwinters only in semitropical regions.

The banded cucumber beetle (Diabrotica balteata Lec.) and the spotted cucumber beetle (Diabrotica undecimpunctata howardi Barber) often injure young cucumber plants, and the striped cucumber beetle (Acalymma vittata $\left(F_{0}\right)$ ) damages the plants and fruits. The melon aphid (Aphis gossypii Glov.) often causes serious damage to cucumbers.

Because of its habit of tunneling into the stalks, vines, buds, flowers, and fruit of cucurbits, the pickleworm has been difficult to control with the insecticides known prior to World War II. Studies conducted near Charleston, S. C., from 1930 through 1934 showed the need for more effective control measures. In 1948 these studies were resumed to determine the control value of some of the newly developed Station.

1/ In conperation with the South Carolina Agricultural Experiment 
Inserticades. In additıon, phytotoxielty experimenis were made io lcarr the effect of the use of insecticides on the growth of the cucumber plaris, as well as residuc determinations and experiments on the effect of lindane on the odor and flavor of the rruit. All these siudies are beng continued, but the progress made through the 1951 season 15 reported herein.

\section{REVIEW OF LITERATURE}

Recommendations for control of the pickleworm prior to 1925 corlsisied chiefly of cultural practices. Quaintance $(16,17)$, Smith $(19,20)$, and Sullivan (21) advocated early planting, destruction of crop remnants, and use of squash as a trap crop in cucumber and cantaloup planings. They considered insecticides of little value. Quaintance and Smith did advise the use of an arsenical spray to combat the melonworm. Cryolite or rotenone-containing materials were among the most effective insectlcides in the discussions of the pickleworm published beiween 1937 and 1947 by While (23), Watts (22), Arant (3,4,5), and Fulton (11). Fulion reported that, except on very small curumbers, cryollie residues were not excessive in North Carolina when the fruits were picked shortly before each dusting. He also obtained promising resulis with certain nicotine dusts. He considered the use of squash as a trap crop to be o: doutiful value and the destruction of dead crop remnanis of no benefit. Ho zeenis to have been the first to express the belief that the pickleworm overwintres only in semitropical regions, where a continuous source of food is available. Our findings 1 recent years substantiate this theory.

In siudies made more recontly in Virginia by Brooks and Anderson (6) and by Anderson and Hofmaster (2), BHC (benzene hexachloride), DDT, and TDE (DDD) proved effective against the pickleworm, but Brooks and Anderson reported that under certain conditions BHC caused severe injury to the new growth of cucumbers and cantaloups. Crowell and Morrison (8) found that all the chlorinated hydrocarbon insecticides secmed capable of inflicting injury to cucurbits. Alban and heirns (1), Carruth and Howe (7), and Mathewman et al. (15), in tests in Ohio, New York, and Cunada, respectively, found a purified grade of DDT having a setting point of about $103^{\circ} \mathrm{C}$. to be less injurious io cucurbits than the technical grade.

The fundangs of kelsheiner (13) 1 fl Flovida 141947 and 1948 and of Dupree and Bockham (?) in Georgha in 1351 regarding the relatibe cffocturness of lindanc, parathirn, purified DDT, and cryolite agree substantially with the data presented in this publenton. Dupree and Beckman alse noted an merease in ne !on aphads following ihe use of purified 1)1) 1 , cryolite, and CS-708 (Dilum). 
Considerable toxicity of the fungicide zineb to the pickleworm and the melonworm was observed in Florida in 1949 by Genung (12) and in South Carolina in 1950 by Reid (18). Genung stated in correspondence that he obtained similar results in Florida in 1950 。

\section{EARLY EXPERIMENTS}

Nine experiments, consisting of field-plot comparisons of several insecticides in the control of the pickleworm and the melonworm on summer squash, were conducted by the senior author near Charleston, S. C., during the fall-crop seasons of 1930 through 1934. Cucumbers and muskmelons were added in 1934. From three to eight, usually four, replications of each insecticide were made on plots from 5 to 16 feet in width (1,3, or 4 rows) and from 120 to 262 feet in length. The plant varieties used were White Bush, Yellow Crookneck, and Cocozelle squash, Early Fortune cucumbers, and Hale's Best muskmelons. The insecticides were applied with a bellows-type knapsack duster early in the morning in 1930-33 and in the early part of the night in 1934. The number of applications ranged from 5 to 12 , and the dosage from 12 to 33 pounds per acre. An exception was a dosage of 54 pounds of a freeflowing lead arsenate-sulfur dust in one experiment. Applications usually were made every 3 or 4 days during the period of greatest insect abundance and every 7 to 10 days thereafter. Sometimes they were discontinued when fruiting began in order to avoid poisonous residues.

The results of these early experiments were based chiefly on yields of sound and wormy (pickleworm-infested) fruits, supplemented by pickleworm and melonworm survival counts in 1934.

The following insecticides were tested:

Lead arsenate, calcium arsenate, and potassium hexafluoaluminate, undiluted and diluted with 5 parts of sulfur, hydrated lime, or a copper-lime fungicide.

Barium fluosilicate, diluted with 5 parts of hydrated lime in one test, and with 1 part of wheat flour and 4 parts of sulfur in another.

Cryolite (natural, containing 89 percent of sodium fluoaluminate), diluted with 1 part talc and 3 parts of sulfur.

Paris green, diluted with $41 / 2$ parts each of hydrated lime and sulfur.

Derris powder, diluted with sulfur and either talc or kaolin, sulfur composing one-third of the mixture, which contained various strengths of rotenone; in one test derris was diluted with tobacco dust to contain 1 percent of rotenone.

Pyrethrum dust, two of unknown pyrethrin content and one diluted with tobacco dust to contain 0.1 percent of pyrethrin $I$. 
Each of the ansectucides gave adequate control of the melonworm. Counts made in 1934 indicated that a 1 -percent rotenone dust gave 91 to 99 percent reduction, a 0.5 -percent rotenone dust 74 to 95 percent, and an uridiluted calcium arsenate dusi 80 to 95 percent. The melonmorm feeds itmost exclusively on plant follage and apparently is not diffacult to combat with insectreides.

"The plckleworm proved much more diffeult to control than the melonworm. Each of the insecticides was of some value, but adequate control was seldom obtaned when the insect was abundant, even though frequest applications were made. Yields of sound frut ohtained from untreated plants were relatively low, no sound of infested squashbeang produced by umireated plots in four experiments. Wormy fruits from untreated plants of the other experiments, during the peak of the pickleworm infestations, ranged from 4.5 to 74 percent of the squish prodaced. Applications made only during the prefrusting stage of squash 6 sow th were ineffective; 55 percent of the fruits were wormy when fivr applıcations of a lead arsenite-sulfur dust were made at that time.

Lead arsenate, potassium hexafluoaluminate, and tastum fluosilifate terded to be more effectre aganst the pickleworm than calcium arsenate and paris green. Yields of sound squash obtained from planis receiving the most eif - Digitized by the Internet-Archivesenate-sulfur

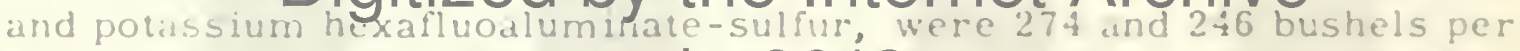
acre, respectuvely, althuugh 10 in 2013 the fruts were infested in eirh case. Untreated plants produced no squash.

In the one exper iment in which it was used, a cryolite-talc-sulfur dust mueased the yield of sound squash by 115 bushels per acre, and only 2 percent of the fruits were infested. In the same experment a 1.j-percent gotenone dust increased the yeld of sound squash by 137 bushels per atre, but 11 percent of the iruits were wormy. Untreated plants in this cxperiment produced no squash.

Dusts contairlug 0.5 and I percent of rotenone gave adequate control of a l.ght pickleworm populatior, but were madequate aganst moderate to heary infestations when used alwe and when preceded hy applications of a lead arsenate-sulfur mixture before the frut appeared. In syte of right appleations of these dusts, 73 and 5 ? percent of the fruts, re sper wroly, became wormy in an experiment wh wheh untreated planis produced no squash. Pyrethrum dusts also were ineffectwe when lised alone and when preeded hy a lead arsenate-sulfur dust.

Sulfur proved to be ul cousiderable value as a fungle ble and apparently of some value as an wusentede on squash. The beld of semend frute was

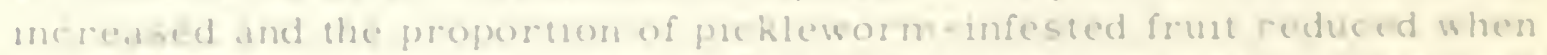

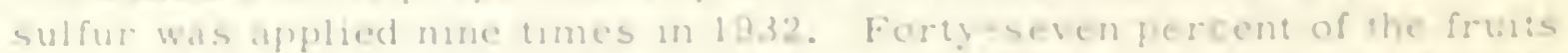

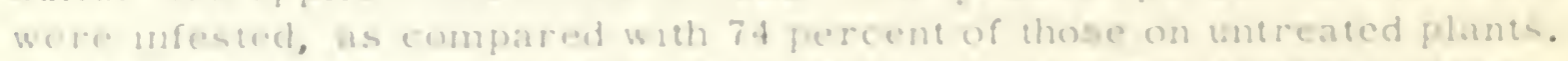


were diluted with sulfur than when used undiluted or mixed with hydrated lime or copper-lime.

In general, the early studies indicated that (1) the pickleworm is more difficult to control than the melonworm, (2) pickleworm mortality counts are impractical after the insects begin tunneling into the plants and fruits, (3) for adequate control the pickleworm must be killed before this tunneling begins, (4) undusted barrier rows and check plots serve as sources of infestation of surrounding plants, and (5) more effective control measures and insecticides involving residues less hazardous than used previously are needed.

\section{PHYTOTOXICITY EXPERIMENTS}

The effect of the periodic use of several new insecticides on the growth of three varieties of cucumbers was determined in the experiments conducted in the spring of 1948 and 1949. Practically no insects were present on cucumbers during these experiments, and all yield differences are considered to be due to the direct effect of the insecticides on the plants.

Each plot consisted of two rows 6 feet wide and 36.3 feet long. The plots were arranged in randomized blocks. Seven applications were made at weekly intervals in 1948 and eight in 1949, beginning about a week after the plants came up (when the second true leaves appeared) and ending the day of the third harvesting in 1948, and that of the first harvesting in 1949. The applications were made in the morning with rotary hand machines on wet to moist plants, with one or two trips per row. Dry plants were sprayed with water before being dusted. A clothcovered hood with a plastic-cloth apron 8 or 10 feet long was often used to reduce insecticide drift.

In 1948 from 8 to 19 pounds per acre were used in the first four dustings and from 20 to 37 pounds thereafter. In 1949 the dosage ranged from 12 to 20 pounds for the first five dustings and from 20 to 26 pounds thereafter. Nine harvestings at 2- to 3-day intervals were made each season.

The yields of marketable cucumbers obtained during these experiments are summarized in table 1.

In 1948 a BHC dust severely bleached and stunted the plants of each variety from the outset, and reduced the yield of the Marketer variety by 35 percent and that of S. C. 5 (a mildew-resistant breeding line) by 69 percent.

In 1949 an impregnated 1 -percent DDT dust made from a commercial dust that was stated to contain 10 percent of purified DDT (setting point $103^{\circ} \mathrm{C}$.) and 23 percent of an aromatic petroleum-derivative solvent significantly affected cucumber yields. It caused chlorosis and stunting of the plants from the outset, the injury being severe after the third 
application. Simplar use of a dust containing only 2 percent of a commercial solvent (a mixture of di- and tri-methyl naphthalenes) on an outside row in the same cucumber planting apparently caused no injury to the plants. Yields of marketable Palmetto cucumbers, a recently. developed mildew-resistant variety, were reduced by 64 percent and those of the S.C. 5 breeding line by 63 percent. The purified, but not impregnated, 3-percent DDT dusi caused slight chlorosis in some S. C. 5 plants and moderate chlorosis in some Palmetto plants by the third applicatın. This injury hecame less apparent as the plants grew, and there was no significant effect on yields. The 5-percent methoxychlor dust caused slight chlorosis in a few plants of each variety, but did not significantly affect the yields.

One percent gamma BHC dusts, prepared from concentrates of approximately 95-percent gamma content, caused no visible plant injury and did not significantly affect yields in either year. The commercial product used in 1948 had little odor when diluted to a 1 -percent gamma dust; that used in 1949 had a slight odor. In 1948 plants of the Markeier variety getting the 1 -percent gamma dust gave slightly higher yields than untreated plants; the reverse was irue of the S. C. 5 breeding line. The yields of dusted plants of both S.C. 5 and Palmetio cucumbers iended to be lower than those of planis not receiving the gamma BHC dusi in the spring of 1949, but the differences are not statistically significant. Lindane was used when it became available in the fall of 1949.

\section{CONTROL EXPERIMENTS}

Thirteen field-plot experiments designed to develop a program for the control of the pickleworm and associated insect pesis on the fall crop of cucumbers were conducted each year from 1948 through 1951. Two experiments were conducted on squash, one each in 1.350 and 1951 .

Each insecticide treatment was used on four to six randomized-block replications of field plots consisting of one row of plants. The rows were 6 feet wide and $361 / 3$ feet long, or $1 / 200$ acre, in all but one resi, in which they were 27 feet long, or $1 / 269$ acre. The dusts were applied in the same way as in the phytotoxiciry tests. The sprays were applied (two or three trips per row) with a kmapsack sprayer that mamtaned a farly constant pressure.

Fungle ape aplications were made separately with power-driven machines, under the direction of a plant pathologist. Sprays were usually applued, but dusts were used when the field was too wet for the sprayer. Dusages ranged from $\$ 0$ to 80 gallons per acre (depending on the size of the plants) of a mixture comtanung 1.3 pounds of zmam or zinel, per 100 gallous of spray. Dusts comtaining 3.? percent of zram or \%nel, were applied at the rate of approximately 20 pounds per acre. 
The fungicides were applied about once a week, beginning about 10 days after seeding and ending 2 to 3 weeks before completion of harvest.

The insecticide applications on cucumbers were made as shown in table 2 .

\section{Control During Early Stages of Plant Growth}

Special efforts were made to find methods of evaluating the effectiveness of insecticides in pickleworm control before yield records could be obtained. Early-season control data were needed for comparison of the more toxic materials, which should be used only during the prefruiting period of plant growth because of residue hazards. In the early experiments examination of squash plants from which yield data were to be secured did not prove feasible, because the plants had to be destroyed to find the larvae that had tunneled into them. The problem was even more complicated with cucumbers, because it was difficult to separate the plants after the vines became entangled. Examination of surplus plants at the time of thinning and of the staminate flowers later were possibilities explored in the fall seasons of 1948 and 1949.

The numbers of surviving insects on surplus plants at thinning time provided an indication of the effect of the insecticides on pickleworms, melonworms, and melon aphids. The information was limited, however, by the small number of plants examined, the small size of the plants, the light infestation usually present at that time, and the few applications ordinarily made before thinning time. In spite of these factors, survival counts of the melonworm and melon aphid at this time seemed worth while.

The number of pickleworms and melonworms (the former comprising about 90 percent of the total) in the staminate flowers shortly before harvest was a reliable index to the effectiveness of the insecticides, being more closely correlated with yield data than counts made at thinning time. The pickleworm control in the flowers was usually higher than that obtained on the fruits. Control data based on flower examinations are limited, because ordinarily only small pickleworms feed in cucumber blossoms and many do not feed there at all. Squash flowers, however, are larger and larvae are able to complete development in them. Flower examinations made as near harvesttime as possible should prove valuable, particularly in work with squash, if yield data cannot be obtained. 


\section{Control During Fruiting Stages of Plant Growth}

Results of the control experiments are based chieny upon the percentage of wormy cucumber fruits of all sizes, the number of wormfree (sound) cucumbers of all sizes and quality, the number (and someimes weight) of worm-free marketable fruits, and the degree of interiscide injury to the plants. Any cucumber that showed a pickleworm entrance hole was classed as wormy. From 7 to 11, usually 9 or 10 , hirvestings were made. Fruits from all plants on each ploi were plcked every 2 or 3 days. All cucumbers remaining on the plants were included in the last harvest. Where all marketable fruits were not weighed, the number required for a bushel was determined at least iwice each season.

Yield data oltained from comparisons of the various insecticides are glven in table 3, and those obtained from use of the more promising of these materials at various application intervals are shown in table 4.

Effects of certain insecticides on a moderate melon aphid infestation that occurred in plots of the 1951 pickleworm-control experiments were determined by picking 10 leaves at random from each plot and separating them into the following classes: Free (no aphids), slight ( 1 to 20 aphids), moderate (21-100 aphids), and heavy (more than 100 aphids). Numerical values were assigned to the various classes as follows: Free 0, slight 1, moderate 5, and heavy 20. The number of leaves occurring in each class was multiplied hy the numerical value of the class, and the product was added to give the infestation rating of the plot (table 5).

In the following discussions the various insecticides are evaluated chiefly on the basis of the percent of the total number of fruits harvested that were wormy (pickleworm infested). Some consideration, however, is given to the relative number of all sound fruits produced, as well as to the yield of marketable cucumbers. In general, an insecinide will he regarded as having given adequate pickleworm control when the wormy fruits did not exceed about 1 or 2 percent of the total. Unless otherwise indicated, the proportions of constituents of the insecticide mixtures are on a weight basis.

Aldrin

A 2.5-percent aldrin dust was one of the materials proving most cffective agamst the puckleworm (tat)le 3). This msecticide did not provide quate adequate control of the heavy 1949 population, but at gave near-adequate protertion against a moderate mfestation in 1951 . When used with zinch), dt gave adequate control of a light infestation 1 in 1950.

Alelrin was mol rested so extensively as lundane. Aldran was not

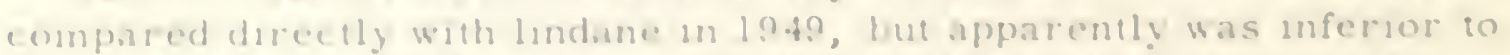
It an that yeat. Aledrut was as cffoctive as landane in 1950 and 1951. Ther was mo appreciable bubl-up of melom aphads on cucumbers treated 
with aldrin in 1951 (table 5). This insecticide showed no phytotoxicity to cucumbers.

\section{Allethrin}

When applied directly on the insects in laboratory cage tests in 1950 , a 0.5 -percent allethrin dust proved toxic to third-instar pickleworms, but it was less effective against last-instar larvae, even when used at a heavy dosage. A 2-percent allethrin dust showed only moderate toxicity to last-instar pickleworms. The addition of 1 percent of piperonyl cyclonene and of compound 469 did not appreciably increase the toxicity of a 0.5 -percent allethrin dust.

In field plots a 1 -percent allethrin dust was of some value against a light pickleworm infestation in 1950, but was not of significant value when a moderate infestation prevailed in 1951 (table 3). Piperonyl butoxide, compound 469, and an activated nicotine did not appreciably increase the effectiveness of a 0.5 -percent allethrin dust in 1951.

\section{BHC}

BHC caused serious injury to cucumbers in the spring of 1948 (table 1) and was not used in later tests. For tests with gamma BHC, see Lindane.

\section{Chlordane}

A 2-percent chlordane dust had no apparent ill effect on cucumbers in the spring of 1948 (table 1), but caused slight to moderate chlorosis of about one-third of the plants in the fall of that year. It was one of the least effective insecticides against the pickleworm in the fall of 1948 (table 3).

Cryolite

Cryolite gave an intermediate degree of control of the pickleworm. It provided adequate protection against the melonworm and cucumber beetles, but apparently increased melon aphid populations on cucumbers. This aphid was more abundant on cryolite-treated plants than on plants receiving any of the other materials in two experiments each in 1948 and 1949. In 1951 populations of this aphid were highly significantly greater on cryolite-treated cucumbers than on untreated plants (table 5).

A cryolite dust of 50-percent sodium fluoaluminate content gave near-adequate control of a moderate pickleworm population when applied every 5 or 7 days in 1948, but not when applied every 10 days (table 4). Weekly applications in 1949 did not give satisfactory protection against a heavy infestation. When accompanied by zineb, a 70 -percent cryolite 
dust gave satisfactory control of a light infestation in 1950 and nearadequate control of a moderate one in 1951 (tables 3 and 4).

Cryolıte usually proved inferior to lindane and purified DDT and superior to methoxychlor. No phytotoxicity of cryolite to cucumber or squash plants was observed. Cryolite residues are discussed on page 17.

CS-674A, CS-645A, and CS-708

CS-674A proved superior to the similar material CS-645\& in 1349 , when used in 2-percent dusts againsi a heavy infestation of the pickleworm, but these materials and a mixture of them known as CS-T08 did not give adequate control (table 3 ). CS-645A was more effective in a spray than in a dust. 15 -percent CS-708 dusi gave adequate protection to cucumbers against a light infestation in 1950, but a 2 -percent dust did not do so against a moderate infestation in 1951 , being infer 10 r 10 a 0.5 -percent lindane dust. Plants receiving CS-708 in 1951 had a higher melon aphid infestation than untreated plants (table 5). The three materials showed no phytotoxicity to cucumbers.

DD'T

In the fall of 1948 a dusi containing 3 percent of a purified, or vinesafe, grade of DDT (setting point $103^{\circ} \mathrm{C}$.) caused no apparent injury 10 cucumbers; a similar strength of technical DDT (setting point $90^{\circ} \mathrm{C}$.) dust caused slight to moderate chlorosis of the foliage. Slight 10 moderate chlorosis of cucumbers, but no yield reduction, resulied from use of the purified grade in 1950. No difference in the degree of control of the pickleworm afforded by the technical and purified grades was indicated in the 1948 fall-season experiment (table 3 ).

The purified grade of DDT gave adequate protection to cucumbers against the melonworm and cucumber beetles and an merrediate degree of control of the pickleworm. Against the pickleworm DDT was usually inferior to lindane, tended to be superior to cryolite, and was superior to methoxychlor. The use of DDT apparenty increased the melon aphid population on cucumbers m 1948 and in 1951 (table 5 ), lut unt somuch as the use of cryolute.

A dust rontaning 3 perecent of purified DDT gave near-adequate control of a molerate pickleworm populaten an 1948 when used every 5 , 7, or 10 days (table i), but not when applied crers 7 to 1 it days (tat le 3$)$. Applicaluons every 7 or 10 days did not gue satisfactory proiciton agamst a heavy infestatuon in $19+9$ (table i). When acrompaned by fmeb and applied ( wery 5 to 10 d.us, thes 3 -pertent dust gave adequate control of a light population in loso (table a) and a similar a-perecent dust gave near-adequate control of a moderase mfestation in tast ( 
Residues at harvest after the use of DDT on cucumbers are discussed on page 17 .

\section{Dieldrin}

In laboratory cage tests in 1950 a 2.5 -percent dieldrin dust gave complete kill of third-instar pickleworms, but only 30 -percent kill of last instars. In a field experiment this dust gave complete control of a light pickleworm infestation in 1950 and adequate control of a moderate infestation in 1951, being among the most effective materials and as toxic as a 1 -percent lindane dust (table 3). Dieldrin gave excellent control of the melon aphid in 1951 (table 5). It showed no phytotoxicity to cucumbers in 1950 and 1951.

A 1 -percent endrin (the stereoisomer of dieldrin) dust was as effective against the pickleworm and the melon aphid as a 2.5-percent dieldrin dust in 1951 (tables 3 and 5). Endrin caused slight to moderate burning and chlorosis of cucumber foliage.

\section{Heptachlor}

A 0.24-percent heptachlor spray ( 2 pounds of a 50-percent wettable powder to 50 gallons) gave good control of a light pickleworm infestation in 1950, but a 2.5-percent dust did not prove very effective against a moderate infestation in 1951 (table 3). The dust apparently gave partial protection against the melon aphid (table 5). Heptachlor showed no phytotoxicity to cucumbers.

\section{Lindane (or gamma BHC)}

Lindane (or gamma BHC) was the most generally effective of the insecticides given extensive trials on cucumbers and squash. Good to excellent control of the pickleworm, as well as of the banded, spotted, and striped cucumber beetles, the melonworm, and the melon aphid, was obtained when a 1 -percent dust of either material was applied every 7 to 10 days at about 20 pounds per acre (tables 3, 4, and 5). Emulsion sprays containing 0.025 to 0.058 percent of lindane applied to give 0.125 to 0.250 pound of lindane per acre and a suspension spray containing 0.06 percent applied at the rate of 0.25 pound of lindane per acre also gave good control of these insects. In 1950 and 1951 weekly applications of a 0.5 -percent lindane dust gave good control of the pickleworm when accompanied by separate approximately weekly applications of zineb.

Gamma BHC and lindane provided satisfactory insect control on several thousand acres of fall-crop cucumbers grown in the vicinity of Charleston, S. C., between 1948 and 1951. 
No phytotoxicity of lindane to cucumber and squash was observed, except that in 1950 the emulsion spray caused a slight chlorosis of small cucumber plants. These plants were not injured by later applications, and their ytelds apparently were not affected. A l-percent lindane dust applied every 5 days sometimes caused slight to moderate injury, such as might result from rexcessive deposits of any dust on cucumber follake.

Preliminary laste tests were made at three locations between 1948 and 1950 by about 83 persons, including men, women, and children, in efforts to determine effects of lindane and gamma BHC on the palatabiluy of cucumber fruits. Experienced tastc panels were not involved in the studies. Approximately 118 comparisons were made of lots of one to three cucumbers from lindane-treated and untreated field plots. Practically all the treated samples came from plants that recelved several applications of either a 1 -percent gamma dust or a spray containing 1 pound of a wettable 25-percent gamma powder to each 100 gallons of water, the last application usually being made the day the samples were harvested. Off-flavor or off-odor of one or more of the fruits in the treated lots was reported in 18 percent of the comparisons, but only a few of them were said to be objectionable. Only two persons are known to have distinguished between all treated and untreated fruits. One of these persons has had considerable taste-panel experience. He stated that the off-flavor probably would not be noticed by the average person.

Lindane has been used extensively in recent years on commercial plantings of fresh market cucumbers in the vicinity of Charleston, S. C. No complaints of an objectionable odor or taste of the fruits have come to our attention. We understand that similar conditions have prevalled in other southeastern States. It is possible that off-flavor following the use of lindane may be more pronounced when the cucumbers are picked when they are small, as usually is done for pickling.

Since potatoes grown in soil treated with lindane may have a musty odor and flavor, as reported by kirkpatrick et. al. (14), tests were made to determane whether the application of lindane to cucumber planings would contaminate the soil sufficiently to affect the flavor of subsequent crops of potatoes. In 1951 five varietics of potatoes--Pontiac, Bliss Triumph, Irish Cobbler. Sebago, and Cherokee--uere grown an plois of Dupont very fine sandy loam soil in whseh cucumbers had been gown in the fall of 1950. The pickleworm had been adepuately controlled on the cueumbers by a total of $1 \mathrm{l} / 4$ pounds of lindane per acre un eight weekly applaciturns. For checks the same varieties of potaloes were grown withan about so yards in a similar freld an wheh landame had never been used. Samples of the potatoes uere tested by an experbenced taste pamel In the Burvan of Human Nutrition and Home Economas. The Irish

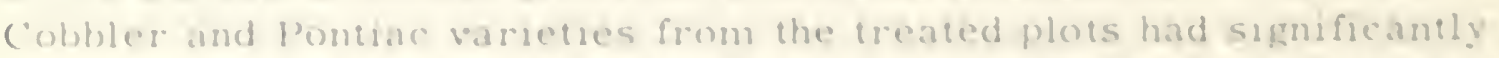

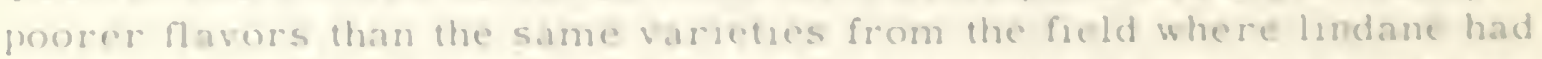
nover heen used. Thr off-flaver was charncterized as musty and char-o metertic of BHC; hut in no sample lested was at mense or extremely 
undesirable. The results with Bliss Triumph were not clear-cut but showed a similar trend, whereas there was no significant off-flavor in the other two varieties.

Insecticide residues on cucumber fruits following field applications of lindane and gamma BHC are discussed on page 17.

Methoxychlor

Methoxychlor proved to be one of the least effective materials against the pickleworm. Inadequate control resulted from the use of a 5-percent dust in 1948 (table 3) and in 1949 (table 4), a 2.5-percent impregnated dust in 1949 (table 3), a 10-percent dust in 1950 and 1951 (table 3), a 0.181 -percent suspension spray in 1949, and a 0.189 -percent emulsion spray in 1949 (table 3). Methoxychlor was inferior to lindane in every comparison and usually proved inferior to cryolite. Methoxychlor was of considerable value in the control of the melonworm in 1948 and 1949 (data not shown in tables). This material did not reduce the melon aphid infestation in 1951 (table 5), but on methoxychlor-treated plants the aphid population was lower than on plants receiving several other insecticides and was no higher than that on untreated plants. Methoxychlor caused slight to moderate chlorosis of cucumber plants, but this injury did not appreciably affect yields. Methoxychlor residues are discussed on page 17 .

Nicotine

Nicotine was used as an additive to control the melon aphid and to increase the degree of pickleworm control given by another insecticide. A cryolite-nicotine dust held the melon aphid in check in 1948 and 1949, but there was an increase in the infestation when cryolite was used alone. Nicotine was of significant value against the pickleworm when used with cryolite in 1949 and tended to be so in 1950 (table 3). However, it was of no significant value against the pickleworm when used with cryolite or rotenone in 1948 (table 3), or when added to rotenone, sabadilla, or pyrethrum in 1950 or to sabadilla and allethrin in 1951 (table 3).

Dusts containing 1 percent of nicotine and 4 percent of either polyethylene glycol (600) monolaurate or bis(p-chlorophenyl) sulfide 2 were ineffective against the pickleworm on squash and on cucumbers (table 3 ) in 1951. Cucumber plants receiving these dusts had significantly higher melon aphid infestations than did untreated plants (table 5). The first mixture caused slight injury, and the second mixture caused severe injury and a reduction in yield. A dust containing 0.5 percent of

2/ These mixtures were supplied by the Bureau of Agricultural and Industrial Chemistry. 
nicoline, 2 percent of polyethylene glycol (600) monolaurate and 20 percent of sabadilla did not give adequate control of the pickleworm in 1951 (table 3).

Parathion

Parathion was among the most effective materials tested, but was not given such extensive trials as lindane, DDT, cryolite, and methoxychlor. It gave good control of the melonworm and the melon aphid in 1948, and of the melon aphid in 1951 (table 5). Parathion was less effective than gamma $B H C$ and lindane against the pickleworm, when used as 1 -percent dusts (tables 3 and 4). A 0.5 -percent parathion dust was inferior to a 0.5 -percent lindane dust against the pickleworm in 1951 (table 3). The residual effect of parathion against this 1 sect did not appear to be so lasting as that of lindane, cryolite, and DDT. Five applications of a 1 -percent parathion dust at intervals of 7 io 8 days gave almost adequate protection to cucumbers against a heavy pickleworm infestation in 1949; four applications of a 0.045 -percent parathion suspension gave excellent control that season (table 3). Similar use of a 1 -percent dust provided adequate control of the lighter infestations in plantings being treated with zineb in 1950 (table 4) and 1951 (table 3). "This insecticide showed no phytotoxicity to cucumbers even though in 1950 as many as seven applications of a l-percent dust were made, beginning when the plants had only one to three true leaves.

A spray containing 0.028 percent of Metacide, a product containing methyl parathion and parathion, was among the least effective materials used against the pickleworm in experiment 1 of 1950 , and did not provide adequate control of this insect (table 3 ).

Pyrethrum

Pyrethrum dusts showed a high degree of toxicity to pickleworms in laboratory cage iests. An impregnated 0.4 -percent pyrethrins dusi gave complete kill of all stages of the pickleworm in 1950 . An 1mpregnated 0.2 -percent pyrethrins dust killed 90 percent of fifth-1nstar lavae. A 0.1 -percent dust killed all fourth mstars, but only 15 perceme of the fifth instars. A 0.3 -percent pyrethrins dust made directly from pyrethrum powder was about as effective as the 0.1 -percent mmpegnafed dust. Addition of 1 percent of piperonyl hutoxide slightly increased the effecenceness of the impregnated 0.1 -percent procthrins dust.

When used under field conditions, pyrethrum dusts did not give adequate protection of cucumbers aganst moderate to heavy infestamons of the puckleworm (table 3), even when the pyethrins content was as high as 1 percent. Piperonyl cyclonene, plperonyl hutexide

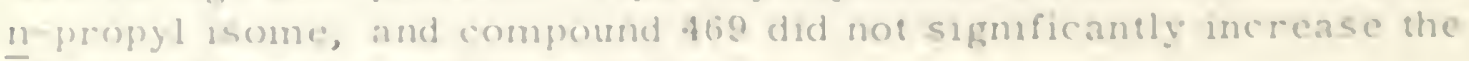
effecesvencess of pyrethrum (table 3 ). 
Q-137

In laboratory cage tests in 1950, average and heavy dosages of a dust containing 3 percent of Q-137 showed only moderate toxicity to third-and fourth-instar pickleworms. A 5-percent dust was one of the least effective insecticides used on field plots in experiment 1 of 1950 , but gave almost adequate control of the light pickleworm infestation (table 3). Q-137 showed no phytotoxicity to cucumbers.

\section{Rotenone}

Insecticides containing rotenone showed little toxicity to fifth-instar pickleworms in laboratory cage tests. A 1 -percent rotenone dust killed only 20 percent of these larvae; a 2 -percent dust killed 70 percent. The effectiveness of a 1 -percent rotenone dust was not appreciably increased by addition of 1 percent of either piperonyl butoxide or compound 469 .

One-percent rotenone dusts did not give adequate control of the pickleworm in field tests (table 3), even though in 1951 they were preceded by lindane and accompanied by zineb. During the fruiting period of cucumber growth in 1950, populations were too low for the value of 1.5 - and 2-percent rotenone dusts to be determined. Addition of piperonyl cyclonene, $n$-propyl isome, nicotine, or mineral oil did not significantly increase the toxicity of a 1 -percent rotenone dust in 1948 and 1949 (table 3). A dust containing 0.15 percent of pyrethrins and 0.5 percent of rotenone was ineffective on cucumbers in 1948 .

Ryania

A dust containing 40 percent of ryania did not give adequate control of the pickleworm in 1948 and 1949 (table 3).

Sabadilla

A 20 -percent sabadilla dust did not provide adequate protection against the pickleworm, but this dust tended to be slightly more effective than rotenone, pyrethrum, allethrin, and ryania dusts (table 3 ). Addition of 0.5 percent of nicotine plus 2 percent of polyethylene glycol (600) monolaurate did not significantly increase its effectiveness in 1951. In the 1950 planting the pickleworm infestation was too low for the value of a 25-percent sabadilla dust, with and without piperonyl butoxide and nicotine, to be determined. 
TDE

A 3 -percent TDE dust was one of the least effective materials used aganst the plckleworm in experiment 1 of 1950 (table 3 ). It was inferior to a 0.5 -percent lindane dust, and caused moderate chlorosis of cucumber foliage.

Tetraisopropyl Pyrophosphate

A l-percent tetraisopropyl pyrophosphate dust was of no apparent value against the pickleworm in experiment 1 of 1949 (table 3 ), and gave only 53 -percent reduction of the melonworm in that year. The material caused no noticeable plant injury.

\section{Effect of Zineb on the Pickleworm}

During the 1950 studies considerable evidence was obtained to substantiate the observations of Genung (12) that the fungicide zineb is moderately toxic to the pickleworm. The unusually low pickleworm infestation on cucumbers in the Charleston, S.C., area in the fall of that year was attributed at least partly to the extensive use, for the first time, of zineb for disease control. Additional evidence of the toxicity of zineb to the pickleworm was obtained by several laboratory cage tesis and a small-scale field-plot experiment on squash (Reid 18).

In experiment 3 of 1951 (table 3) two 4 -percent zineb dusts prepared from different commercial brands of that fungicide significantly reduced the number of pickleworm-infested cucumbers, but did not give adequate protection. Both dusts caused slight chlorosis of the foliage and also a significant increase in the melon aphid population (table 5).

The partial control of the pickleworm with zineb gave promise in 1951 of making possible adequate control of that insect with lower dosages of lindane than previously used, thereby reducing the danger of poisonous residue, off-flavor, and soil contamination. Five applications of a 0.5 -percent lindane dust gave excellent protection to cucumbers aganst a moderate pickleworm infestation in experiment 1 of 1951 (table 3), when accompaned by weekly applications of zuneb. In another planting receiving similar applications of zineb, a l-percent lindane dust applised a week before and at the tume the furst fruts appeared gave almost complete protection through the seventh of 12 harvestings of cucumbers. A dust contannmg 0.25 percent of lindane and 0.1 percent of pyrethrans applied shortly after the seventh harvesting gave almost aclecpuate protection thereafter to this planting (exprement 2 of 1251 . tahle 3). Seproate applatutuns of pyrethrum, sabadilla, and rotenone were of very lithe value. 


\section{RESIDUE STUDIES}

Representative samples of cucumbers from plants treated with certain insecticides shortly before or during the fruiting period, or at both times, were collected in 1948 and 1949 by W. J. Barbour, resident inspector of the Food and Drug Administration, and sent to the Atlanta, Ga., office for residue determinations. Similar samples were furnished the Division of Insecticide Investigations of this Bureau in 1950. The cucumbers were of slicing size, averaging about $21 / 4$ inches in diameter and 0.65 pound in weight. Some of the 1948 samples were run through a brushing and waxing machine, and some of the 1949 samples through a more elaborate washing, waxing, and polishing machine. The treatments of the various samples and the findings of the chemists are shown in table 6 .

The quantity of residue from the different insecticides and from different samples of certain insecticides varied considerably. The only residues of appreciable quantity were those that followed the use of gamma BHC in the fall of 1948 during the fruiting period, and of cryolite in the spring of 1949. Similar applications of gamma BHC in the spring of 1949 and of lindane in the falls of 1949 and 1950 apparently resulted in little or no residue at time of harvest. Cryolite residues were rather variable and sometimes as high as 82 p.p.m. of fluorine. It is not understood why plants that received the last cryolite application on May 23, 1949, before the fruits appeared on the plants, produced fruits showing 9.6 p.p.m. of fluorine. A control program in which lindane was used during the prefruiting period and cryolite thereafter resulted in residues of 0.6 p.p.m. of gamma BHC and 2 p.p.m. of fluorine. The fluorine residue was reduced to 0.2 p.p.m. by washing and waxing of the fruits. DDT, parathion, and methoxychlor residues were low, even when these materials were applied on the day of harvest. The lindane and cryolite residues were reduced as much as 80 to 90 percent by commercial brushing (or washing) and waxing machines. These machines may not have reduced the residues to safe levels, however. Similar findings for cryolite have been reported by Fulton (11).

\section{SUMMARY}

The pickleworm (Diaphania nitidalis (Stoll)) and the melonworm (Diaphania hyalinata (L.)) are serious pests of fall crops of squash and cucumber in the South Atlantic and Gulf States. They also frequently cause damage in adjoining States and occasionally as far north as Illinois and Connecticut. These insects spread northward each spring and summer from semitropical areas. The melon aphid (Aphis gossypii Glov.) and several species of cucumber beetles cause damage to cucurbit crops at times. 
Experments conducted between 1930 and 1934 showed that adequate protection aganst the melonworm and a fair degree of control of the plckleworm could be obtained by frequent applications of lead arsenate, potassium hexafluoaluminate, cryolite, or barium fluosilicate. Calcium arsenate, paris green, pyrethrum, and rotenone usually were less effective against the pickleworm. Sulfur proved to be of considerable value as a fungicide and of some value as an insecticide in the dust mixtures.

In 1948 laboratory cage and field-plot experiments were undertaken to develop more effective and safer measures for the control of the pickleworm and associated insects. Lindane was the most effective material given extensive trial. A 1 -percent lindane dust applied weekly at the rate of about 20 pounds per acre, or sprays providing a comparable dosage, gave excellent control of all insects present on cutumbers and squash. There were indications, however, that the use of lindane during the fruiting period may impart a slight off-flavor or off-odor to cucumbers, and that certain varieties of Irish potatoes may be similarly affected when that crop immediately follows lindane-ireated cucumbers.

Parathion, although iested less extensively than lirdane, proved only slightly less effective against the pickleworm and was as toxic as lindane to the melon aphid and the other insects. A purified grade of DDT ustially proved inferior to lindane but superior to cryolite against the pickleworm. However, a marked increase in the melon aphid population often followed the use of DDT and cryolite. Aldrin, dieldrin, and endrin showed considerable promise against both insects in limited trials.

Insecticides that proved less effective against the pickleworm were chlordane, methoxychlor, CS-674A, CS-645A, CS-708, teiraisopropyl pyrophosphate, TDE, $Q-137$, heptachlor, Metacide, and nicotune plus either bis(p-chlorophenyl) sulfide or polyethylene glycol (600) monolaurate.

Dusts containing rotenone, pyrethrum, sabadilla, allethrin, and ryantu did not provide adequate protecton to cucumber fruits against moderate to heavy infestations of the prchleworm, even when supplemented with several additives.

Zuneb was found to have some toxicity to the prekleworm. Weekly use of this materal for dreease control did not give adequate protecen to cucumbers and squash hewinst that inseet, but evidenty pade at

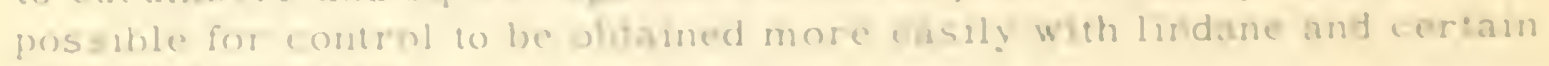
other insectucides.

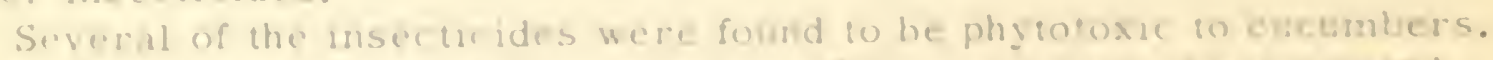

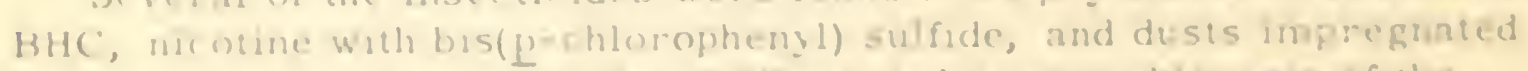
with both techuseal and purafed DDT caused severe chtorosis of the plants and greaty reduced the yield of frums. Less sermous mugry io the plints and no apparent effect on selds resuled from use of ordnary 
DDT dusts (both grades) and of TDE, methoxychlor, chlordane, endrin, zineb, and nicotine plus polyethylene glycol (600) monolaurate.

Insecticide residues as high as 12.2 and 82 p.p.m., respectively, were found on cucumbers when gamma BHC and cryolite were applied weekly until the day of harvest. These residues were reduced to 7.7 and 16.2 p.p.m., by a commercial brushing or washing machine. Residues that followed similar use of lindane, purified DDT, parathion, and methoxychlor were not more than 1.6 p.p.m.

\section{LITERATURE CITED}

(1) Alban, E. K., and Keirns, V. E.

1948. The effect of rotenone, commercial, and aerosol grade DDT dusts on the total yield, grade, and maturity of seven cucurbit varieties. Amer. Soc. Hort. Sci. Proc. 51: $448-452$.

(2) Anderson, Lauren D., and Hofmaster, Richard N.

1948. Control of pickleworms on cucumbers and cantaloupes. Jour. Econ. Ent. 41:334-335.

(3) Arant, F. S.

1940. A progress report on the use of rotenone dusts for the control of the pickleworm and the melonworm in Alabama. Jour. Econ. Ent. 33: 840-843.

(4)

1941. Rate of application of derris-talc dusts for pickleworm control. Jour. Econ. Ent. 34:520-521.

(5)

1942. Effectiveness of derris and cube in pickleworm control. Jour. Econ. Ent. 35: 870-872.

(6) Brooks, James W., and Anderson, Lauren D.

1947. Toxicity tests of some new insecticides. Jour. Econ. Ent. 40: $220-228$.

(7) Carruth, L. A., and Howe, W. L.

1948. Factors affecting use and phytotoxicity of DDT and other insecticides for squash borer control. Jour. Econ. Ent. 41: 352-355.

(8) Crowell, H. H., and Morrison, H. E.

1950. The phytotoxicity to cucurbits of some new insecticides. Jour. Econ. Ent. 43: 14-16. 
(9) Dupree, Minter, and Beckham, C. M.

1952. Progress report of insecticide tests for control of pickleworm on cucurbits. Ga. Agr. Expt. Sta., Mimeo Series 39,8 pp.

(10) Fulion, B. B.

1347. Biology and control of the pickleworm. N.C. Agr. Exp?. Sta. Tech. Bul. 85, 27 pp.

(11) Genung, William G.

1949. Dithane dust indicates effective control of melon worm and pickle worm. Fla. State Hort. Soc. Proc. 62: 130-132.

(12) Kelsheimer, E. G.

1949. Control of insect pests of cucumber and squash. Fla. Agr. Expt. Sta. Bul. 465, 15 pp.

(13) Kirkpatrick, Mary E., Mountjoy, Beatrice M., Albright, Linda C.,

Poos, Fred W., and Weigel, Charles A.

1951. Flavor and odor of cooked potatoes as affected by use of lindane and benzene hexachloride as insecticides.

Amer. Potato Jour. 28: $792-799$.

(14) Matthewman, W. G., Harcourt, D. G., Cass, L. M., and Friend, W. G.

1950. The varietal reactions of cucumbers to DDT and methoxychlor dust. Canad. Ent. 82: 102-111.

(15) Quaintance, A. L.

1899. Some important insect enemies of cucurbits. Ga. Expt. Sta. Bul. 45, pp. $36-41$.

(16)

1901. The pickle-worr. Ga. Agr. Expt. Sta. Bul. 5i, 34 pp.

(17) Reid, W. J., Jr.

1951. Zinc ethylene bisdithiocarbamate toxic to pickleworm and melonworm. Jour. Econ. Ent. 44: 817-818.

(18) Smith, R. I.

1910. Insect enemses of cantaloupes, cucumbers and related plants. N. C. Agr. Expt. Sta. Bul. 205, pp. 29-35.

1911. Two mportant camaloupe pres:s. N. C. Agr. Expt. Sta. Bu1. 214, pp. 105-126. 
(20) Sullivan, K. C.

1924. The pickleworm and its control. Mo.Agr. Expt. Sta. Cir.122, 4 pp.

(21) Watts, J. G.

1939. Insect control investigations - The pickleworm. S. C. Agr. Expt Sta. A. R.521, pp. 189-193.

(22) White, W. H.

1937. Recommendations for the control of insects attacking certain vegetables, small fruits, and tobacco. U.S. Bur. Ent. and Plant Quar. E-376, 14 pp. 


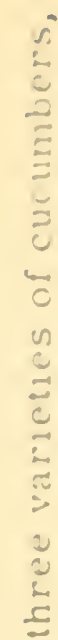

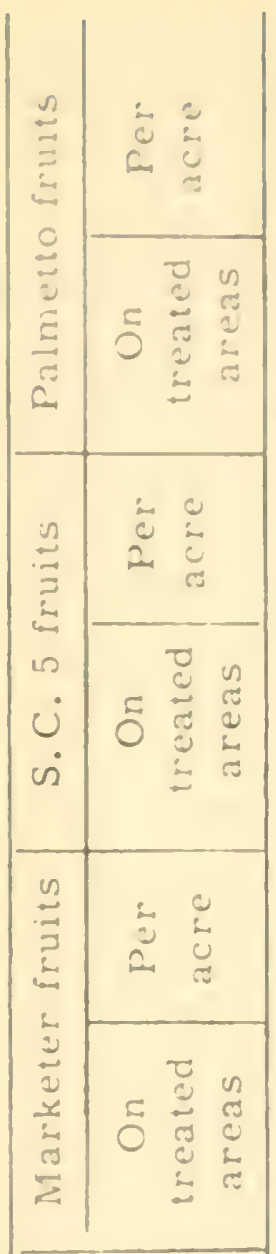

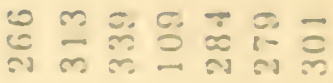

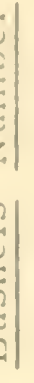

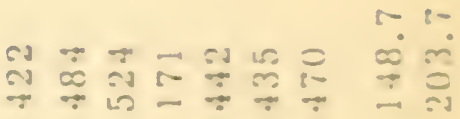

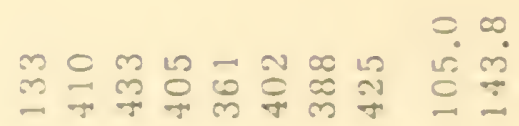

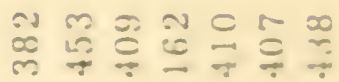

2
0
है
$z$
$z$

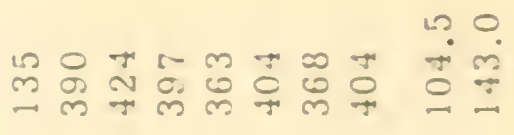

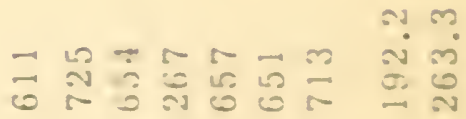

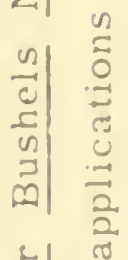

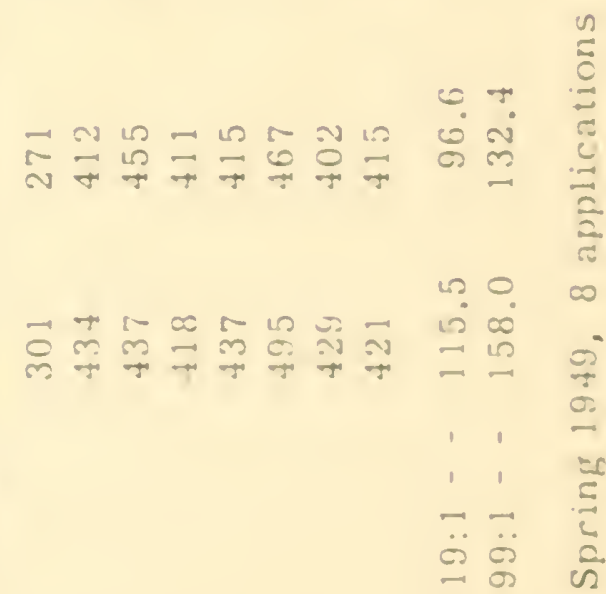

है

ह

范

वृ

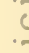

$\because$

2

$\stackrel{\Omega}{=}$

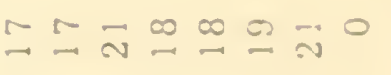

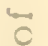

is in

00

$<2$

है भ

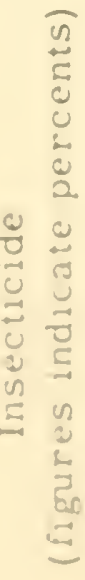

:

है

$\frac{n}{0}$

$\Rightarrow 0 \approx x \omega \infty 0$

물

들

$\stackrel{1}{\tilde{E}}-$

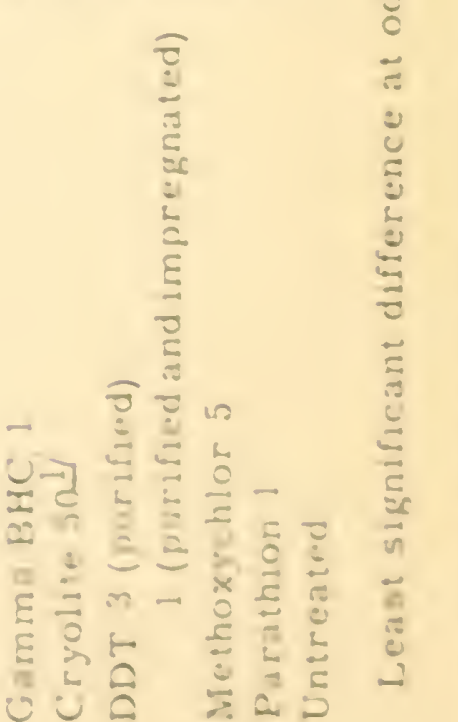

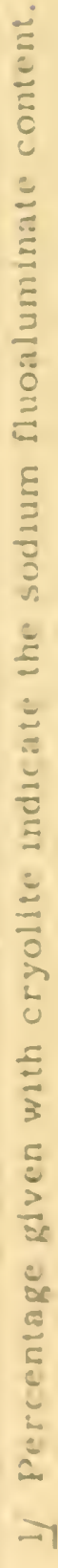




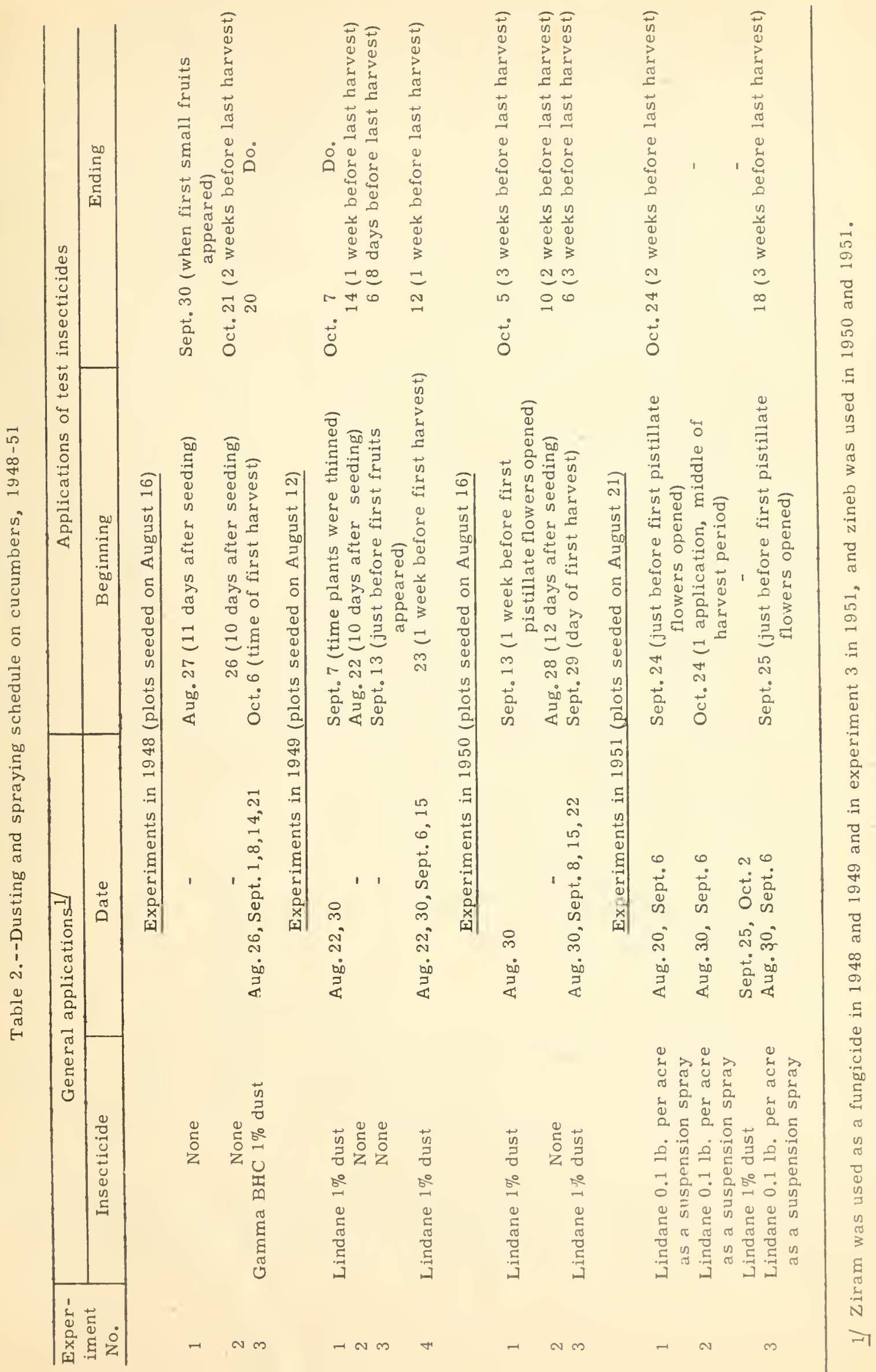


I able 3.--Control of the pickleworm on fall cucunbers with various msecicides, 1948-51. All unsecelicides applied as dusts except where sprays are indicated.

\begin{tabular}{|c|c|c|c|c|}
\hline \multirow{2}{*}{$\begin{array}{l}\text { Insecticide } \\
\text { (figures indicate percent) }\end{array}$} & \multirow{2}{*}{$\begin{array}{l}\text { èberaze } \\
\text { dosage } \\
\text { per acre }\end{array}$} & \multicolumn{2}{|c|}{$\begin{array}{l}\text { All cucumbers } \\
\text { harvesied }\end{array}$} & \multirow{2}{*}{$\begin{array}{l}\text { Markeiable } \\
\text { cucughers } \\
\text { per acre }\end{array}$} \\
\hline & & Sourd & 11.0:8.: & \\
\hline
\end{tabular}

1948, Experiment 1 ( 4 applications at 7 - to 14 -day intervals)

Gamma BHC 1

0.5

Parathion 1

DDI 3

\section{3 (purified)}

1 plus pyrethrins 0.12 (both impregnated) 20

1 (impregnated)

1

Cryolite 50 plus nicotine 1

$$
50
$$

Methoxychlor 5

Rotenone 1

Chlordane 2

Least significant difference at odds

19 pounds
18

18

17

18

20
19

20

18

20

19

17

22
55

37

36

24

22

7

20

16

23

19

15

13

9

10

$2 \div$

18

56

60

30

31

67

51

56

53

65

71
24

13

13

8

8

2

7

5

a

7

5

\&

3

\section{$99: 1 \ldots \ldots . . .-\ldots 9.1$}

1948, Experiment 3 ( 3 applications at 7 -day intervals)

Gamma $\mathrm{BHC} 1$

Sabadilla secd powder 20

Ryania powder $\$ 0$

Pyrethrins 0.3

$$
.15 \text { plus rotenone } 0.5
$$

Rotenone 1 plus piperenty eyclonene 0.5

1 plus micome 1

1 plus oil $\frac{1}{1 / 2}$

1 plus oil 1

$$
1
$$

0.25 plus pueronyl c yeloneme
25

27

27

31

30

26

29

26

26

28

$3 ?$

Lintrented

$$
\text { ..) plus piperomyl iyclonem } 0.5
$$

Lecast sigmificant difference at odds of $19: 1$

394

306

320

309

313

275

283

287

270

230

230

265

230
69

56

63

65

63

5 -

51

52

55

41

ำ

5 \&

33

1) Highly refined, paraffu-base mineral oul of apploximate! is secoads

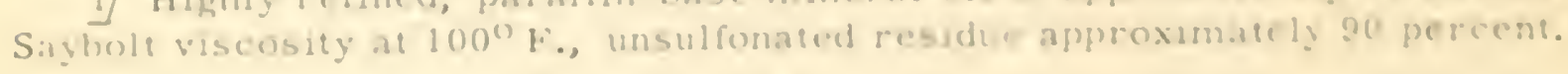


Table 3.--Continued

\begin{tabular}{|c|c|c|c|c|}
\hline \multirow{2}{*}{$\begin{array}{c}\text { Insecticide } \\
\text { (figures indicate percent) }\end{array}$} & \multirow{2}{*}{$\begin{array}{c}\text { Average } \\
\text { dosage } \\
\text { per acre }\end{array}$} & \multicolumn{2}{|c|}{$\begin{array}{c}\text { All cucumbers } \\
\text { harvested }\end{array}$} & \multirow{2}{*}{$\begin{array}{l}\text { Marketable } \\
\text { cucumbers } \\
\text { per acre }\end{array}$} \\
\hline & & Sound & Wormy & \\
\hline
\end{tabular}

1949, Experiment 1 (5 applications at 7 - to 8 -day intervals)

Parathion 1

Aldrin 2.5

CS- 7083

CS-674A 2

Cryolite 50 plus nicotine 2 and lime 5 50

CS-645A 2

Methoxychlor 2.5 (impregnated)

Tetraisopropyl pyrophosphate 1

Untreated

Least significant difference at odds of 19:1 -
23 pounds $473 \quad 10$

$22 \quad 503 \quad 15$

$23 \quad 380 \quad 32$

$22 \quad 354 \quad 34$

$21 \quad 297 \quad 36$

$22 \quad 224 \quad 47$

23

22

22

$187 \quad 52$

$130 \quad 64$

$52 \quad 77$

$45 \quad 74$

134

151

119

104

97

80

66

46

19

17

34.1

45.6

1949, Experiment 3 ( 4 applications at 6 - to 10 -day intervals)

Parathion 0.045 (suspension spray)

CS-645A 0.094 (emulsion spray)

Methoxychlor 0.181 (suspension spray) .189 (emulsion spray)

Untreated

Least significant difference at odds of

Lindane 0.047 (emulsion spray)

1949, Experiment 4 ( 4 applications at 6- to 7 -day intervals)
Sabadilla seed powder 20

Pyrethrins 1

$$
\begin{aligned}
& 0.3 \text { plus piperonyl cyclone } \\
& .3 \text { plus } \text { n-propyl isome } 1 \\
& .3
\end{aligned}
$$

Rotenone 1 plus piperonyl cyclonene 1

$$
1 \text { plus } \underline{\text { n-propyl isome } 1}
$$$$
1
$$

Ryania 40

Untreated

Least significant difference at odds of 19:1 -
66

66

66
66 gallons 246

218

48

34

15

0.8

4

75

77

89

$19: 1$

$93.5 \quad 27.9$
39.2

66

131.1

2

107

96

16

14

6

60.5

84.9

194
125

141

112

112

103

117

96

116

103

69

24.8

33.1 


\begin{tabular}{|c|c|c|c|c|}
\hline \multirow{2}{*}{$\begin{array}{c}\text { Inscectrade } \\
\text { (flgures indicate percent) }\end{array}$} & \multirow{2}{*}{$\begin{array}{c}\text { Averabe } \\
\text { dosag } \\
\text { per acte }\end{array}$} & \multicolumn{2}{|c|}{$\begin{array}{l}\text { All clicumtera } \\
\text { harvesied }\end{array}$} & \multirow{2}{*}{$\begin{array}{l}\text { Marketable } \\
\text { evcumbers } \\
\text { per are }\end{array}$} \\
\hline & & Sound & Worm! & \\
\hline
\end{tabular}

1950, Experiment 1 (4 applications at 7 - to 8-day trierva!s)

D) $101 \mathrm{dr} \ln 2.5$

Lindane ().06 (ausperision spray) .5

Aldran 2.5)

Hepiachlor 0.24 (susperision spray) CS-70) 5

0.125 (ometsionspray)

Cryolite 70 plus nicotine 2 and lime 5 $i()$

TDE 3

Methoxychlor 10

$Q-1375$

Meracide. 0.028 (cm lision spras)

Untruated

Least sigmefeant dufference (Including untroated plots) at odds of $19: 1$

$$
\text { ก: } 1
$$

24 pounds 843

47 gallons 1,059

22 pounds 872

24

$90 !$

27

47 gallons

951

23 pounds

892

832

47 gallons

.09

26 pounds

24

24

25

23

47 galions coul

800

852

867

787

831

$6+8$
0

0.1

265

333

273

273

286

268

273

276

297

256

$28 \%$

270

237

$20 !$

219

$\$ 8.6$

64.8

Least significant difference (excludug untreatrod plots at odds of $19: 1 \ldots \ldots$

$99: 1 \ldots \ldots \ldots 2.2$

$195\left(1, E x_{1}\right.$ (riment 3 (2 appluatums at 7 -day dntervals)

Sabadilla seed powder 25

$$
\begin{aligned}
& 25 \text { plus puperonyl } \\
& \text { butoxide } 1 \\
& 25 \text { plus neotine } 2.5
\end{aligned}
$$

Pyrethrins (umpregnated) 0.2

.2 plus lindane 0.25

.2 plus nicotine 2.5

.2 plus compound 2 plus pherrongl

hutoxide l
28 pounds 873

272

30

30

26

25

30

26

24
891

874

879

378

826

ก 49

783
277

269

278

285

238

297

228

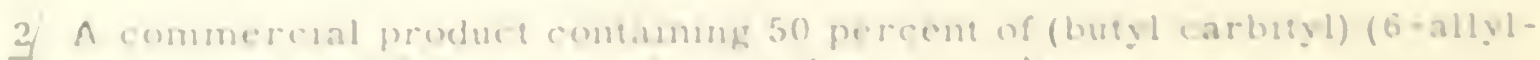
piperombl) format and 30 prerceme of relatod iompounds. 
Table 3. - Continued

\begin{tabular}{|c|c|c|c|c|}
\hline \multirow{2}{*}{$\begin{array}{c}\text { Insecticide } \\
\text { (figures indicate percent) }\end{array}$} & \multirow{2}{*}{$\begin{array}{l}\text { Average } \\
\text { dosage } \\
\text { per acre }\end{array}$} & \multicolumn{2}{|c|}{$\begin{array}{c}\text { All cucumbers } \\
\text { harvested }\end{array}$} & \multirow{2}{*}{$\begin{array}{l}\text { Marketable } \\
\text { cucumbers } \\
\text { per acre }\end{array}$} \\
\hline & & Sound & Wormy & \\
\hline \multicolumn{4}{|c|}{ Number Percent } & Bushels \\
\hline
\end{tabular}

Pyrethrins (impregnated) $0.075 \mathrm{plus}$ rotenone 0.375 and piperonyl cyclonene

\subsection{5}

Rotenone 2

1.5

1.5 plus nicotine 2.5

Allethrin 1

1 plus piperonyl butoxide 1

Untreated

Least significant difference at odds of 19:1 -

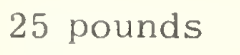

26

26

26

28

24
823

982

845

919

808

781

.798
255

315

252

284

264

248

257

\section{1, Experiment 1 ( 5 applications at 5 - to 10 -day intervals)}

Lindane 1 느
0.5

Cryolite 50

DDT 2 (purified)

Parathion 0.5

Untreated

Least significant difference at odds of 19:1 -
20

21

20

21

20

20
773

856

852

639

737

827

405
190

194

194

137

169

196

108

34.7

46.7

\section{1, Experiment 2 (1 application)}

Sabadilla 20

20 plus nicotine 0.5 and polyethylene glycol (600) monolaurate 2

Pyrethrins (impregnated) 0.15

.1

.1 plus lindane 0.25

.1 plus piperonyl

butoxide 1
36

541

20

173

29

536

14

$472 \quad 30$

$449 \quad 31$

$632 \quad 10$

$450 \quad 28$
172

162

158

185

151

3/ Data not significant according to the $F$ test.

4f Four applications. 


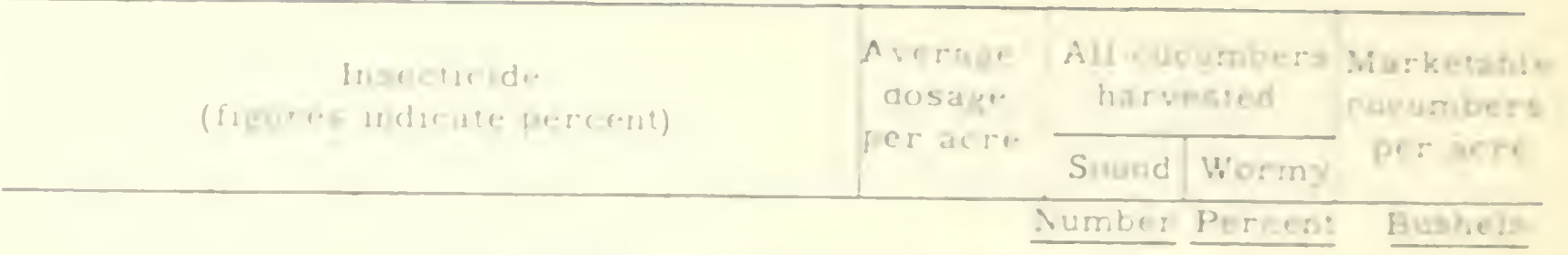

1951, Experdment 2 (corimued)

Rritenose 1

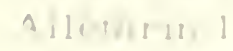

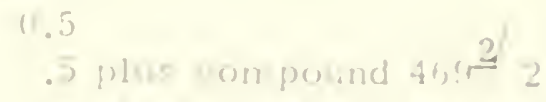

.5 ouns plyetonyl lutoxide 1

.5 plus mentin. (1).5 and pol:-

ethylear glycol (600)

notolararite ?

TEPP (). Ut (spray)

Lnirenered

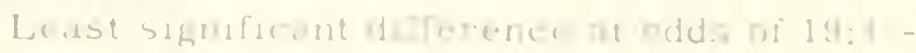

25 pounds

25

25

25

25

(3) $14: 1-$

$\begin{array}{ll}-90 & 13 \\ 481 & 26 \\ 4-i & 31 \\ 205 & 2 i \\ 476 & 211\end{array}$

$: 36$

171

157

162

76.3

$\begin{array}{llll}29 & 454 & 28 & 162 \\ 73 \text { g.1lons } & \text { iso } & 25 & 173 \\ - & 364 & 27 & 141\end{array}$

162

41

6.2

10.9

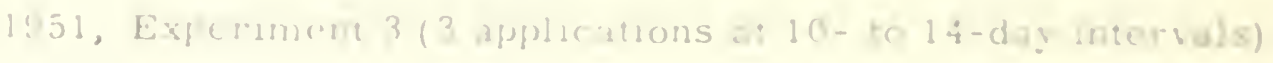

Endrion 1

Diolurin 2.5

Landine 1

$$
\begin{aligned}
& \text { (1).5 } \\
& . \text { () } 25 \text { (cmul=ion spray) }
\end{aligned}
$$

Aldin $2 .$.

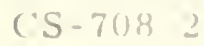

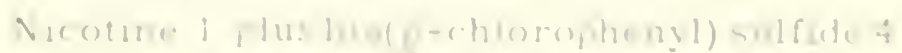

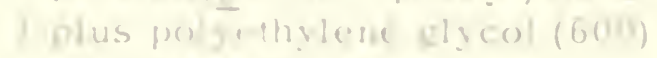

$$
\text { morginitati a }
$$

Methosihlor in

Hopeacher 2.5)

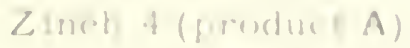

$$
\text { (firodurt B) }
$$

Intresied

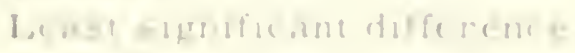

23 pounds

25

2.3

2.2

4.) gallons

23 pownds

21

$2+4$

23

21

2.

23

22
572
608
653
584
618
580
35

$186^{\circ}$

267

$\therefore 03$

is 1

$2+5$

31.3

200

$\begin{array}{ll}9.7 & 154 \\ 2 & 166 \\ 2 & 150 \\ 4 & 176 \\ 1 & 176 \\ 1 & 157 \\ 21 & 112 \\ 3 ! & 59\end{array}$

35

$2 \div$

24

a)

96

52
154

$16 \overline{6}$

130

1.6

76

$15 \%$

12

59

60

130

140

a?

104

ii

31.0

11. 4

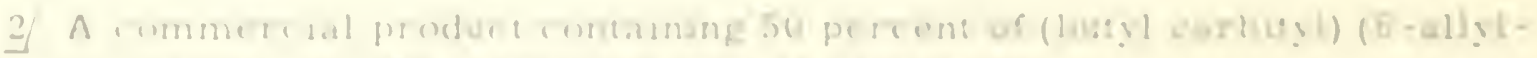
mupronyl) formul and 30 perreme of relded rompousds. 


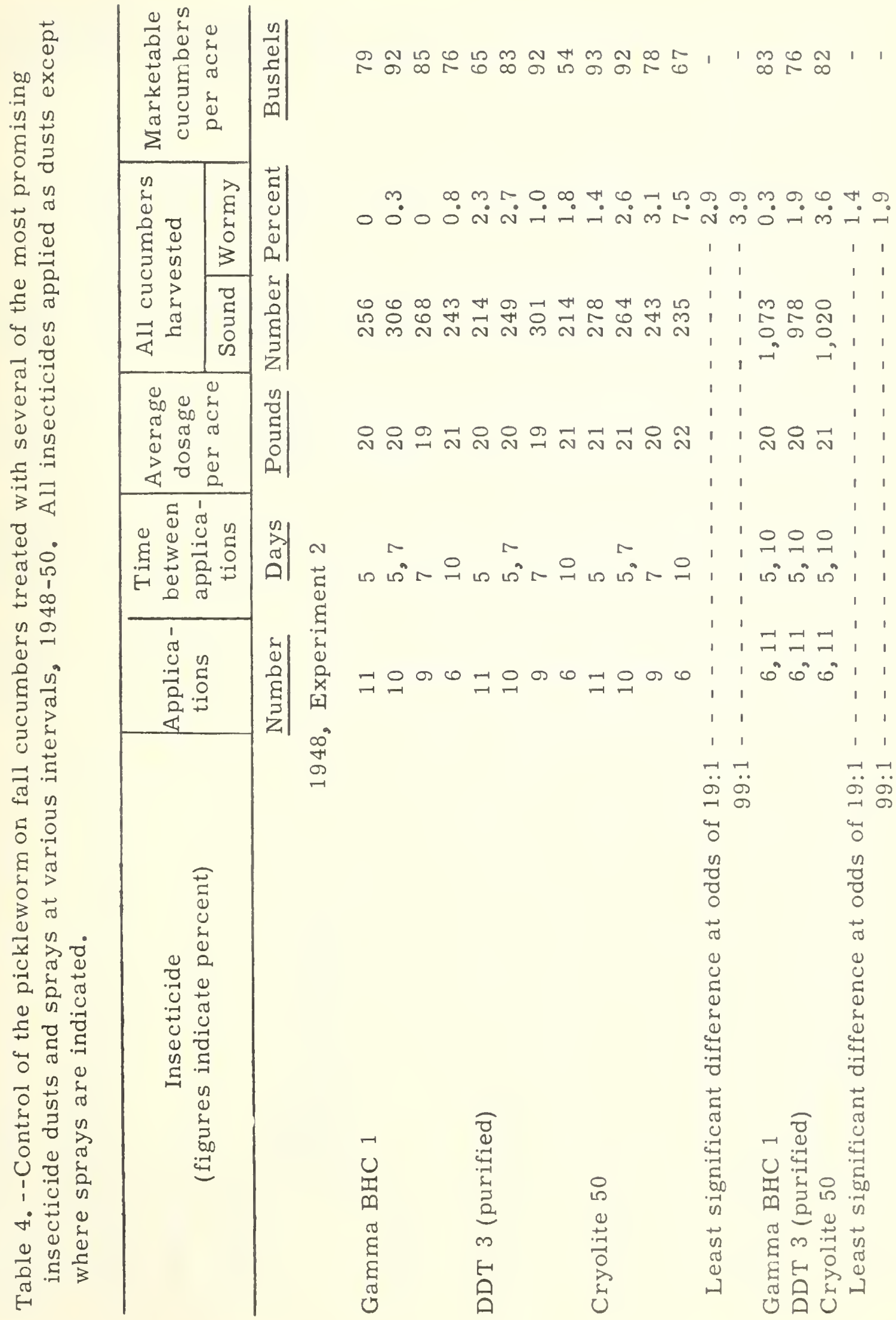




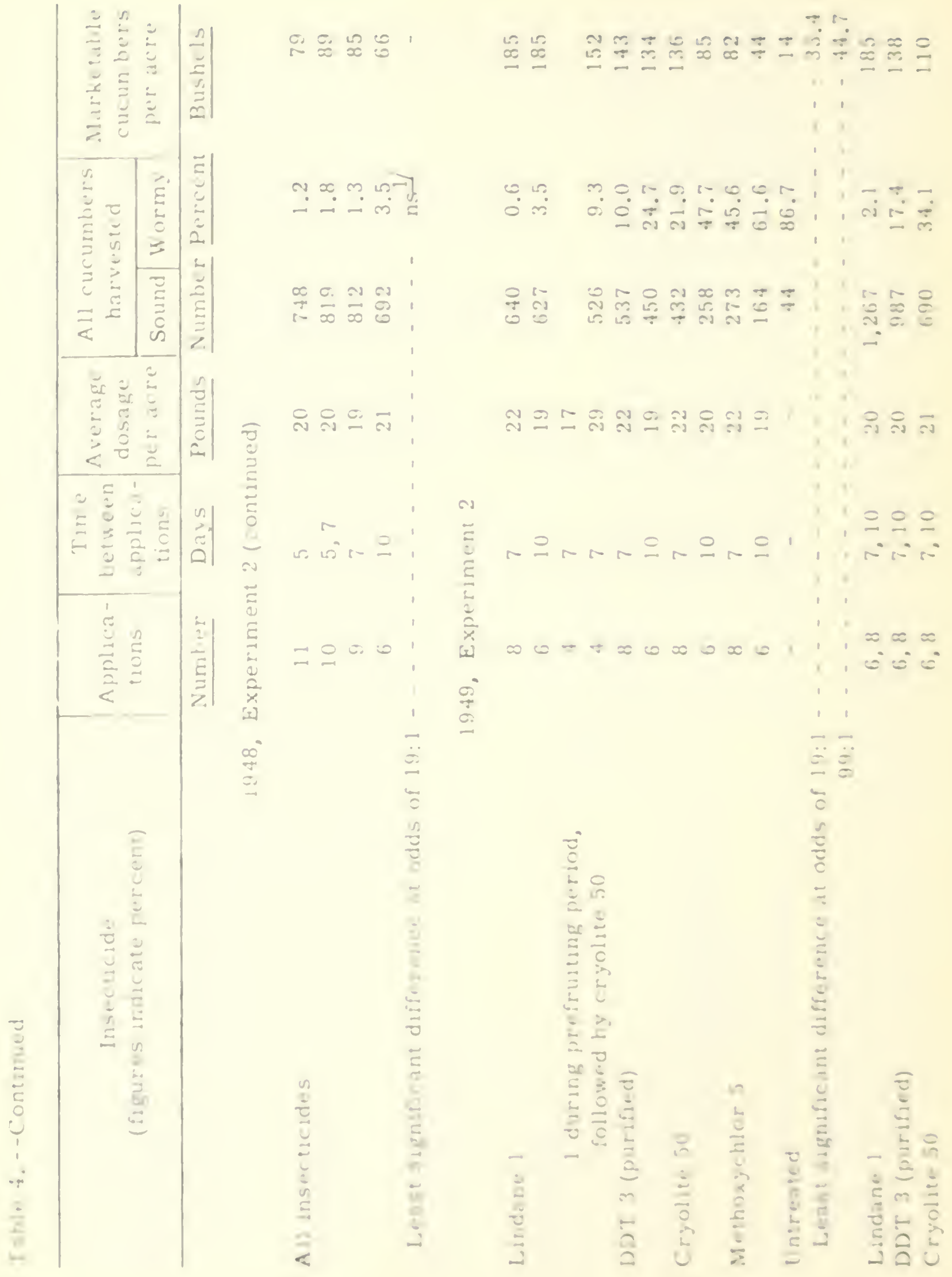




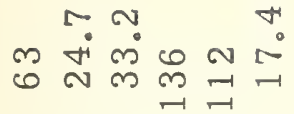

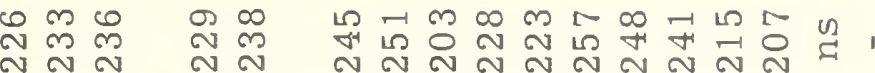

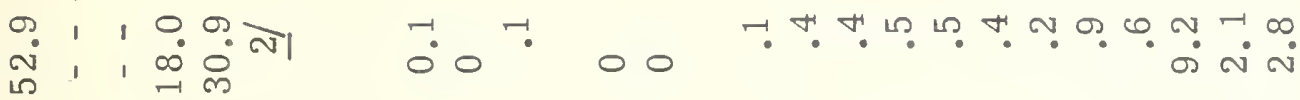

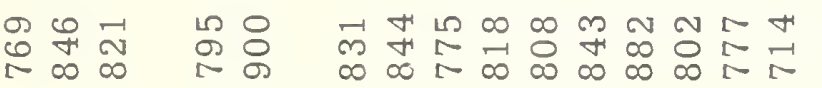

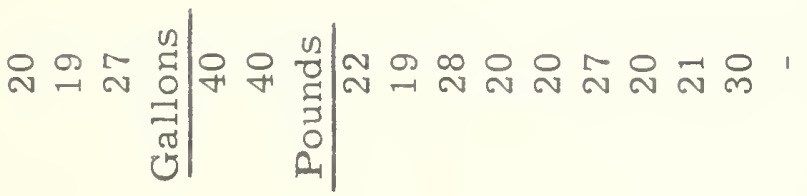

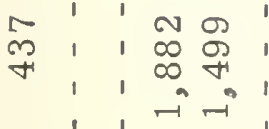

$\begin{array}{llllll}0 & 1 & 1 & 0 & 0 & 1 \\ 0 & 1 & 1 & 1\end{array}$

$\bigcirc \quad 1 \quad 1$

$\therefore 1101$

$\begin{array}{llllll}\infty & 1 & & & 1 \\ 1 & 1 & & 1 \\ & 1 & 1 & & & 1 \\ 0 & 1 & 1 & \infty & 0 & 1\end{array}$

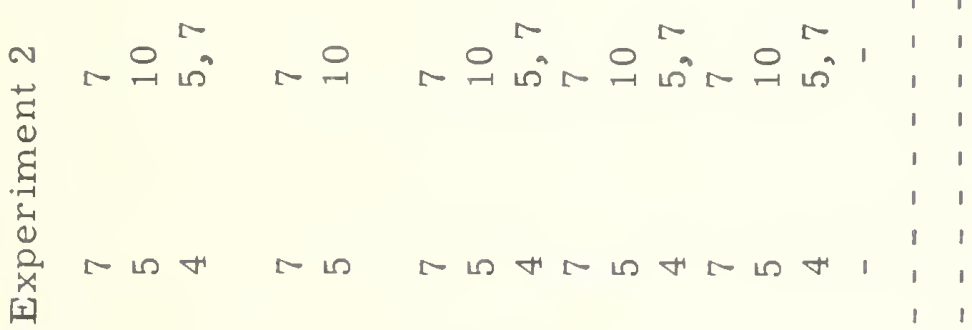

or



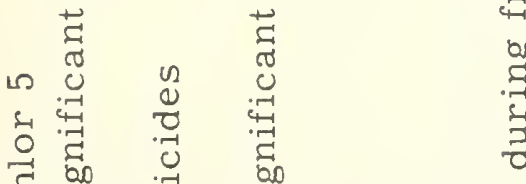

ב

$>$ u u in

希

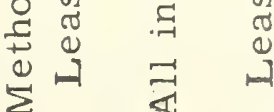

בְ
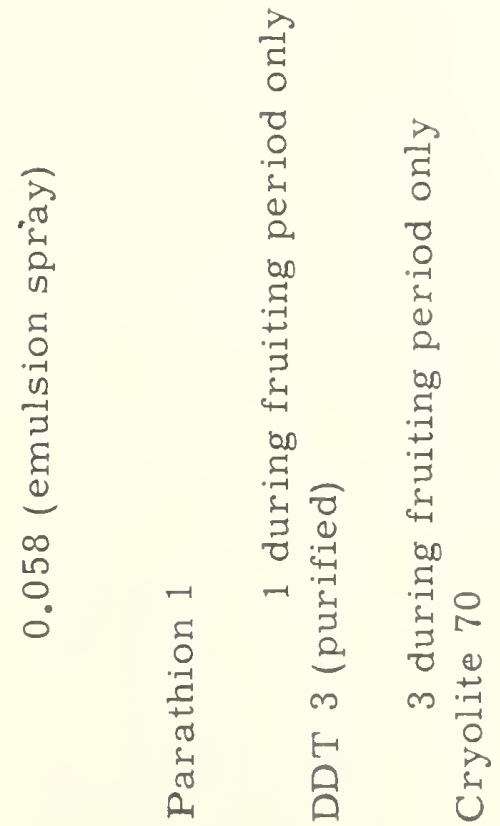

$-1$

$\because \ddot{\sigma}$

4

0

U

ब

$\infty$

4

n

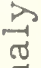

శ。

도

ธี

7

ช

อ

0

3

$\lambda$

$\stackrel{्}{\varpi}$

$\pi \frac{1}{0}$

己.

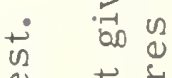

$\stackrel{\square}{0} \stackrel{2}{0}$

I I 10

일

क

읨 $\stackrel{\pi}{\rightleftarrows}$

a $\because \begin{array}{ll}0 \\ 0\end{array}$

.

我岂

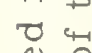

$\leftarrow$ \& 0

$\because \frac{1}{2}$

ए 0

(1)

on

is $\frac{0}{0}$

00

is

(1)

1)

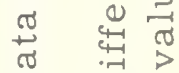

ค ค

$\rightarrow$ 


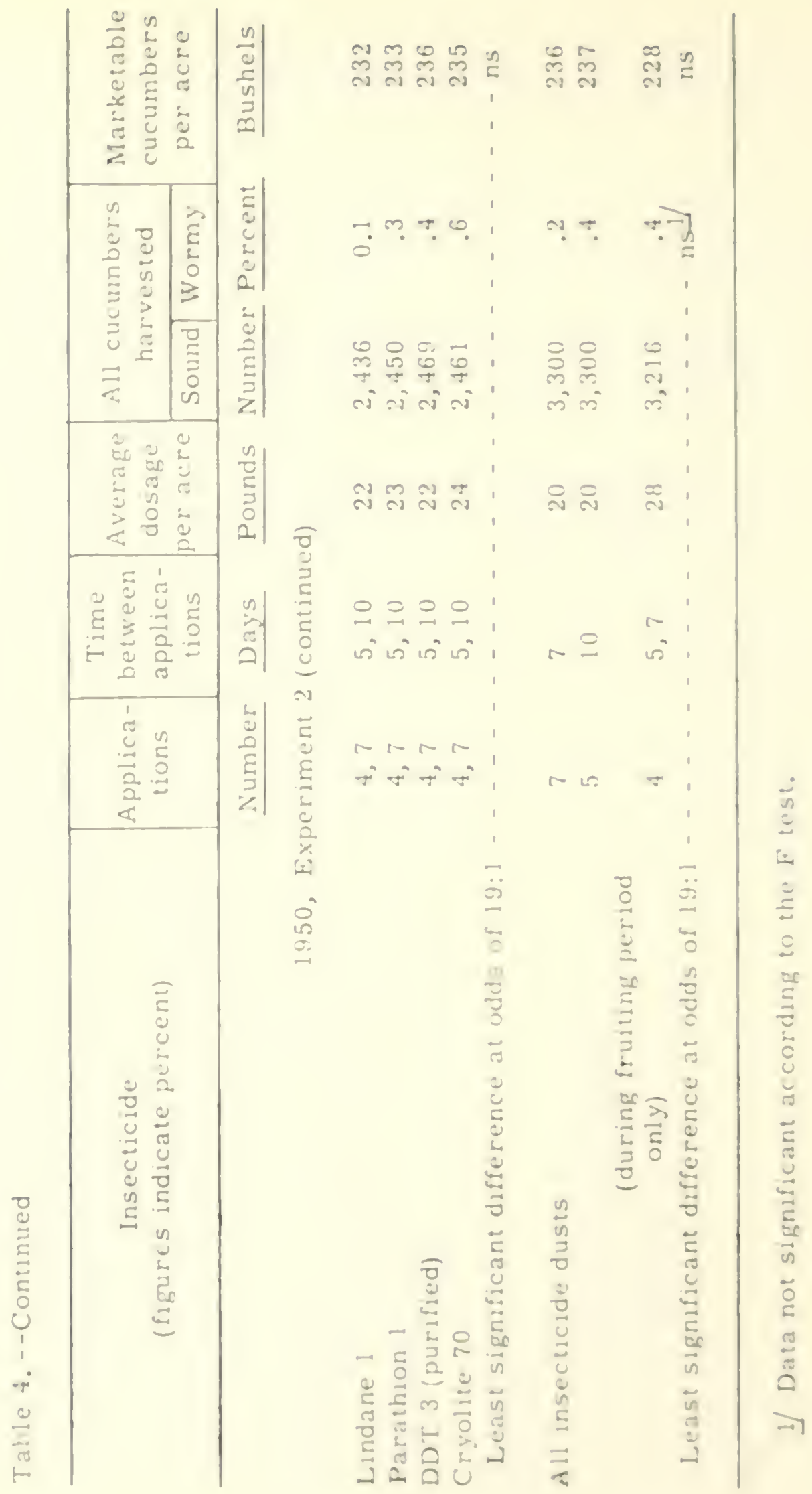


Table 5.--Infestations of the melon aphid on fall cucumbers treated with several insecticides for pickleworm control, 1951. All insecticides applied as dusts unless otherwise indicated.

\begin{tabular}{|c|c|c|c|}
\hline \multirow{2}{*}{$\begin{array}{c}\text { Insecticide } \\
\text { (figures indicate percent) }\end{array}$} & \multirow{2}{*}{$\begin{array}{c}\text { Average } \\
\text { dosage } \\
\text { per acre }\end{array}$} & \multicolumn{2}{|c|}{$\begin{array}{l}\text { Melon aphid } \\
\text { index rating } 1 \text { / }\end{array}$} \\
\hline & & Count 1 & \begin{tabular}{|l|} 
Counts \\
1 and 2 \\
\end{tabular} \\
\hline \multicolumn{4}{|c|}{$\underline{\text { Pounds }}$} \\
\hline \multicolumn{4}{|c|}{ Experiment 1 ( 5 applications at 5 - to 10 -day intervals } \\
\hline Parathion 0.5 & 20 & 0 & 3 \\
\hline Lindane 1 (4 applications) & 21 & 8 & 25 \\
\hline 1 & 20 & 5 & 32 \\
\hline 0.5 & 20 & 16 & 44 \\
\hline DDT 2 (purified) & 20 & 78 & 221 \\
\hline Cryolite 50 & 21 & 247 & 701 \\
\hline Untreated & - & 40 & 108 \\
\hline Least significant difference at odds of $19: 1$ & 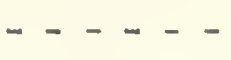 & 53.1 & 100.5 \\
\hline $\begin{array}{llll}29: 1 & 99\end{array}$ & $-\cdots-$ & 71.5 & 135.4 \\
\hline \multicolumn{4}{|c|}{ Experiment 3 ( 3 applications at 10 - to 13 -day intervals) } \\
\hline Dieldrin 2.5 & 25 & 8 & 25 \\
\hline Endrin 1 & 23 & 5 & 37 \\
\hline Lindane 1 & 22 & 9 & 50 \\
\hline 0.5 & 22 & 17 & 77 \\
\hline Aldrin 2.5 & 23 & 23 & 65 \\
\hline Heptachlor 2.5 & 22 & 38 & 268 \\
\hline Methoxychlor 10 & 21 & 201 & 597 \\
\hline CS-708 2 & 21 & 313 & 997 \\
\hline $\begin{aligned} \text { Nicotine } 1 \text { plus bis( }(\underline{p} \text {-chlorophenyl) sulfide } 4 \\
1 \text { plus polyethylene glycol }(600)\end{aligned}$ & 24 & 293 & 1,025 \\
\hline monolaurate 4 & 23 & 304 & 1,082 \\
\hline \multirow{3}{*}{$\begin{array}{l}\text { Zineb 4, product } B \\
\text { product } A\end{array}$} & 22 & 336 & 822 \\
\hline & 22 & 357 & 1,165 \\
\hline & Gallons & & \\
\hline Lindane 0.025 (emulsion spray) & 45 & 16 & 79 \\
\hline Untreated & - & 130 & 745 \\
\hline Least significant difference at odds of $19: 1$ & $-\cdots-\cdot$ & -141.4 & 345.2 \\
\hline $99: 1$ & $--\cdot-\cdot$ & -188.6 & 460.4 \\
\hline
\end{tabular}

1/ Counts were made 1 week apart during the middle of the harvesting period. 


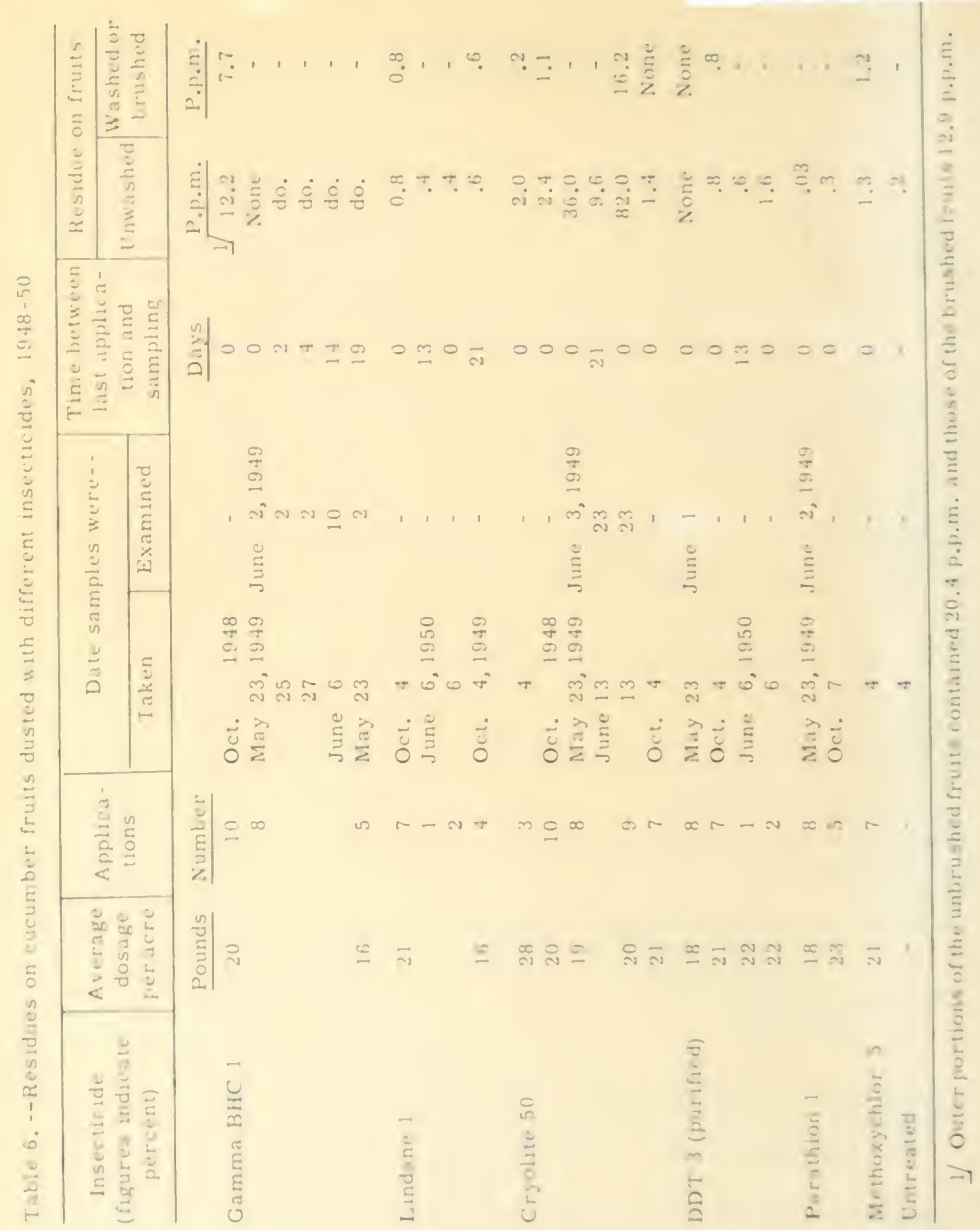

